\title{
The Changing Landscape in the Treatment of Metastatic Castration-Resistant Prostate Cancer: Where are we in 2017?
}

\author{
Carlos Sécio Faria ${ }^{1}$, Ricardo Leão ${ }^{2}$, Bruno Jorge Pereira ${ }^{3^{*}}$ \\ ${ }^{1}$ Faculdade de Ciências da Saúde, Universidade da Beira Interior (FCS-UBI) \\ ${ }^{2}$ Division of Urology, Department of Surgical Oncology, University of Toronto, Princess Margaret, Ontario, Canada And \\ Faculdade de Medicina da Universidade de Coimbra, Coimbra, Portugal \\ ${ }^{3}$ Serviço de Urologia do Centro Hospitalar Cova da Beira (CHCB) and Faculdade de Ciências da Saúde, Universidade da \\ Beira Interior (FCS-UBI)
}

Received: May 29, 2017; Accepted: August 11, 2017; Published: August 19, 2017

*Corresponding author: Bruno Jorge Pereira, Serviço de Urologia do Centro Hospitalar Cova da Beira (CHCB), Quinta do Alvito 6200-251, Covilhã, Castelo Branco - Portugal, Tel: (+351) 929074696 / (+351) 239 041024; Email(s):brunoalexpereira@fcsaude.ubi.pt / brunoalexpereira@gmail.com | bagjp@ubi.pt

\begin{abstract}
Objective: Androgen Deprivation Therapy (ADT) has been the standard treatment for patients with metastatic prostate cancer. Treatment response is usually of short duration and evolves to a state of metastatic castration-resistant prostate cancer (mCRPC). Here, we intend to review the past and new trends in mCRPC treatment.

Materials and Methods: A literature review was performed using Pubmed, Medline, Science Direct and Scielo databases and reference lists from prominent articles. Articles were retrieved from 2001 to 2016 and filtered for relevance and publication type.

Results: Chemotherapy with docetaxel had been the gold-standard treatment for mCRPC. Other agents were, meanwhile, approved: Cabazitaxel, Abiraterone, Enzalutamide and Sipuleucel-T. Bone targeted agents were also developed: Denosumab and Alpharadin (Radium-223). It should be stressed that there are several agents that didn't demonstrated effectiveness, while others are still under study.

Conclusion: mCRPC treatment landscape is changing rapidly. New therapies have revolutionized the treatment of $\mathrm{MCRPC}$. The approved first-line agents are docetaxel, sipuleucel-T, abiraterone, enzalutamide and alpharadin. The timing of second-line treatment remains unclear although it is advisable to start immediately after progression. The current challenge is to understand how to optimize the use of the latest approved agents, and what is the best treatment sequence for these specific groups of prostate cancer patients.
\end{abstract}

Keywords: mCRPC; Chemotherapy; Hormonal therapy; Immunotherapy; Novel Agents

\section{Introduction}

Prostate cancer is the most common malignancy and the second leading cause of cancer death in the Western world [1].Over several years, ADT (Androgen Deprivation Therapy), which consists in bilateral orchiectomy (surgical castration) or administration of neurohumoral substance(s) designated LHreleasing hormone (LHRH) agonists or antagonistsalone or in combination with antiandrogenic drugs (chemical castration), has been considered the standard treatment for metastasized Pca (Prostate Cancer)[2]. Even though there is an initial favorable response this is usually of short duration and disease progresses to a stage called as mCRPC. In this situation continued testicular androgen suppression in CRPC (Castration-Resistant Prostate Cancer) is debatable [3]. However, in the absence of prospective data, the modest potential benefits of a continuing castration outweigh the minimal risk of treatment. In addition, all subsequent treatments have been studied in men with ongoing androgen suppression and therefore it should be continued indefinitely in these patients [2].
Treatment with docetaxel was considered the gold-standard treatment for mCRPC until recently. Nowadays there are other several first-line therapies in mCRPC described above and that may be followed according to the AUA Castration Resistant Prostate Cancer Summary Flowchart (Figure 1):

-Docetaxel - in patients with symptomatic disease and/or visceral metastases or mildly symptomatic or asymptomatic, with no evidence or visceral metastasis both with good performance status 0 or +1 ;

-Abiraterone - mildly symptomatic or asymptomatic, with no evidence or visceral metastasis, with good performance status 0 or +1 ;

-Enzalutamide - mildly symptomatic or asymptomatic, with no evidence or visceral metastasis, with good performance status 0 or +1 ;

-Sipuleucel-T - mildly symptomatic or asymptomatic, with no evidence or visceral metastasis, with good performance status 0 or +1 ;

-Alpharadin - in patients with performance status +2 with evidence of progressive disease;

-Monitoring and conventional anti-androgens - in patients with performance status +2 asymptomatic.

Eastern Cooperative Oncology Group Performance Status (ECOG-PS) was used to stratify patients. Generally, men with a Performance Status (PS) of 0-1 are likely to tolerate treatments and those with PS of 2 or more are less likely to benefit. However, it is important that treatment decisions are individualized and in particular, where symptoms related to disease progression are determining, PS may be appropriate to trial novel treatments in order to see if response is accompanied by an improvement in PS.

The timing of second-line treatment remains unclear in MCRPC although it is clearly advisable to start immediately in men with symptomatic metastatic disease. All patients who receive docetaxel-based chemotherapy for CRPC will progress, thus, there have been many clinical trials investigating the role of salvage chemotherapy [2]. There are several second lines therapies (depending on previous treatments): docetaxel, abiraterone, enzalutamide, cabazitaxel and alpharadin.

The poor prognosis of mCRPC and the reduced quality of life of these patients have encouraged research for more effective systemic therapies. During the last decade, there were identified new therapeutic targets and multiple drugs were developed for mCRPC. The aim of this study is to present and give some insights about how to use the main currently available therapeutic agents 
for the treatment of mCRPC, as well as new agents and molecular targets under investigation with potential benefits in OS, symptomatic relief and quality of life of these patients, thus reducing morbidity and mortality associated.

\section{Materials and Methods}

A literature search using mainly PubMed, Medline, Science Direct and Scielo was held. Articles were retrieved on November 2016 and filtered for relevance and publication type. English language articles published between years 2001 and 2016 were captured in our search. Keywords used were "prostate cancer", "chemotherapy" and "metastatic castrate resistant prostate cancer". Finally, the references of important articles on the topic were consulted for further augment the publication list quality and comprehensiveness.ClinicalTrials.gov database was also reviewed for ongoing clinical trials in the field of mCRPC.

\section{Results and Discussion}

\section{Cytotoxic Agents}

Chemotherapy of patients with CRPC is usually reserved for symptomatic patients with metastatic disease. Patients with non-metastatic CRPC may only receive a chemotherapeutic agent in the context of clinical trials [4].
Chemotherapy can reduce serum PSA (Prostate-Specific Antigen) levels in patients with hormone-refractory prostate cancer and relieves pain in some patients, but tolerability is of concern, due to most of patients are elderly and have other medical conditions associated [5].

Docetaxel is a clinically well-established anti-mitotic agent, which reversibly binds with high affinity for microtubules. It was the first to demonstrate improvement in the quality of life and OS in patients with MCRPC [6].In the TAX327 study 1.006 patients were randomized to receive docetaxel $\left(30 \mathrm{mg} / \mathrm{m}^{2}\right.$ weekly or $75 \mathrm{mg} / \mathrm{m}^{2}$ every 3 weeks) plus prednisone or mitoxantrone $(12 \mathrm{mg} /$ $\mathrm{m} 2$ every 3 weeks) plus prednisone. Results showed favorable benefits in the3weekly docetaxel group in terms of OS (18,9 months versus 17,4 months with weekly administration versus 16,5 months in the mitoxantrone group) (Table 1 ) [6]. SWOG-9916study also revealed and compared docetaxel with mitoxantrone against estramustine. The results of this study in regard to OS were, again, favorable to the first group (17,5 vs 15,6 months) (Table 1) and docetaxel was approved for the treatment of castrate-resistant prostate cancer by the FDA (Food And Drug Administration) and the EMA (European Medicines Agency) in May and November 2004, respectively (Figure 1) [7]. Meanwhile, estramustine was sparingly used due to its thromboembolic effects.

Table 1: Phase III trials of the approved agents for the treatment of mCRPC

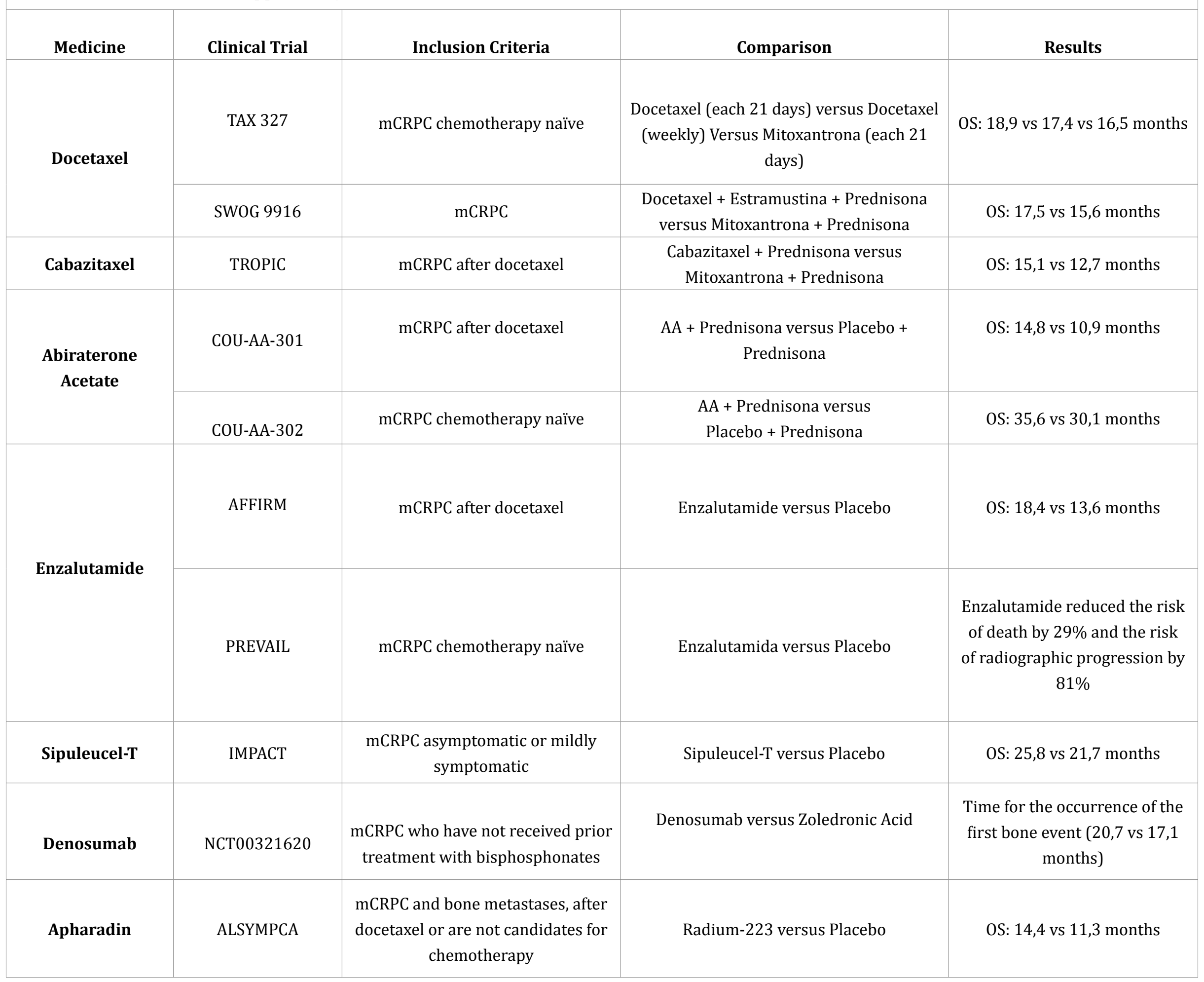




\section{Staging/H\&P/Imaging Algorithm}

\begin{tabular}{|l|}
\hline \multicolumn{1}{|c|}{} \\
\multicolumn{1}{|c|}{ Index Patient 1} \\
\hline \multicolumn{1}{|c|}{ CRPC } \\
\hline $\begin{array}{l}\text { RECOMMENDATION } \\
\text { Observation with continued androgen } \\
\text { deprivation } \\
\text { OPIION } \\
\text { First-generation anti-androgens } \\
\text { (flutamide, bicalutamide and rilutamide) } \\
\text { OR tirst-generation androgen synthesis } \\
\text { inhibiturs (ketoconazole + steroid) } \\
\text { to select patients unwilling to accept } \\
\text { observation }\end{array}$ \\
\hline
\end{tabular}

\begin{tabular}{|c|}
\hline Bone Health \\
\hline RECOMMENDATION \\
\hline $\begin{array}{l}\text { Preventative treatment (e.g. supplemental } \\
\text { calcum, vitamin D) for fractures and skeletal } \\
\text { related events } 10 \text { CRPC potients } \\
\text { OPTION }\end{array}$ \\
\hline $\begin{array}{l}\text { Choose either descosumiab or zoledunic acid } \\
\text { when selecting a preventative treatment for } \\
\text { skeletal relaved events for mCRPC patients } \\
\text { with bony metastases }\end{array}$ \\
\hline
\end{tabular}

Copyright 22015 American Urological Association Education and Research, Inc

$\downarrow$

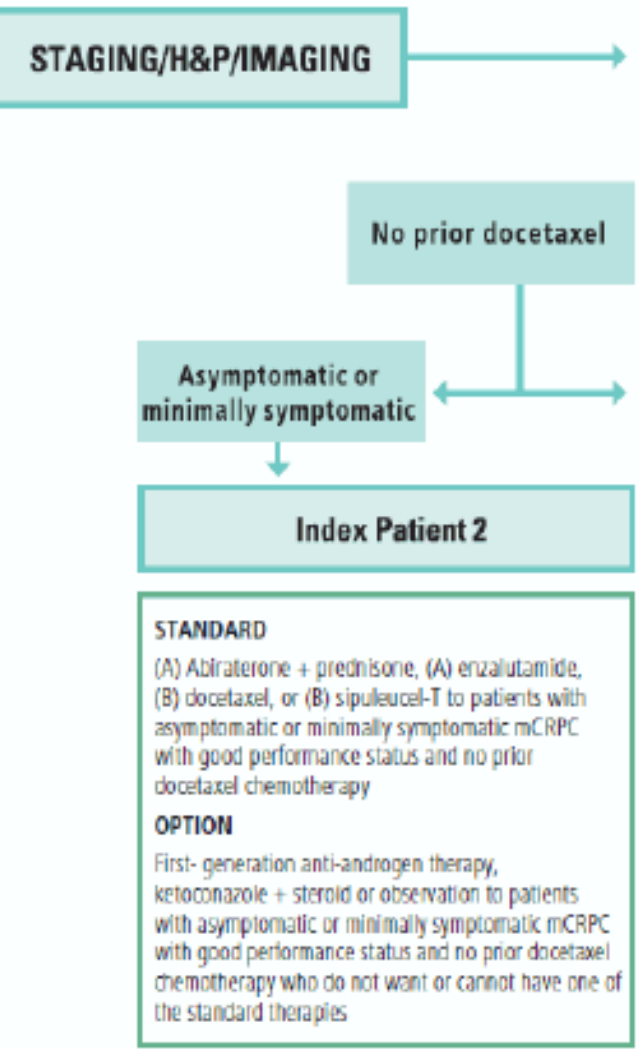

Metastatic CRPC
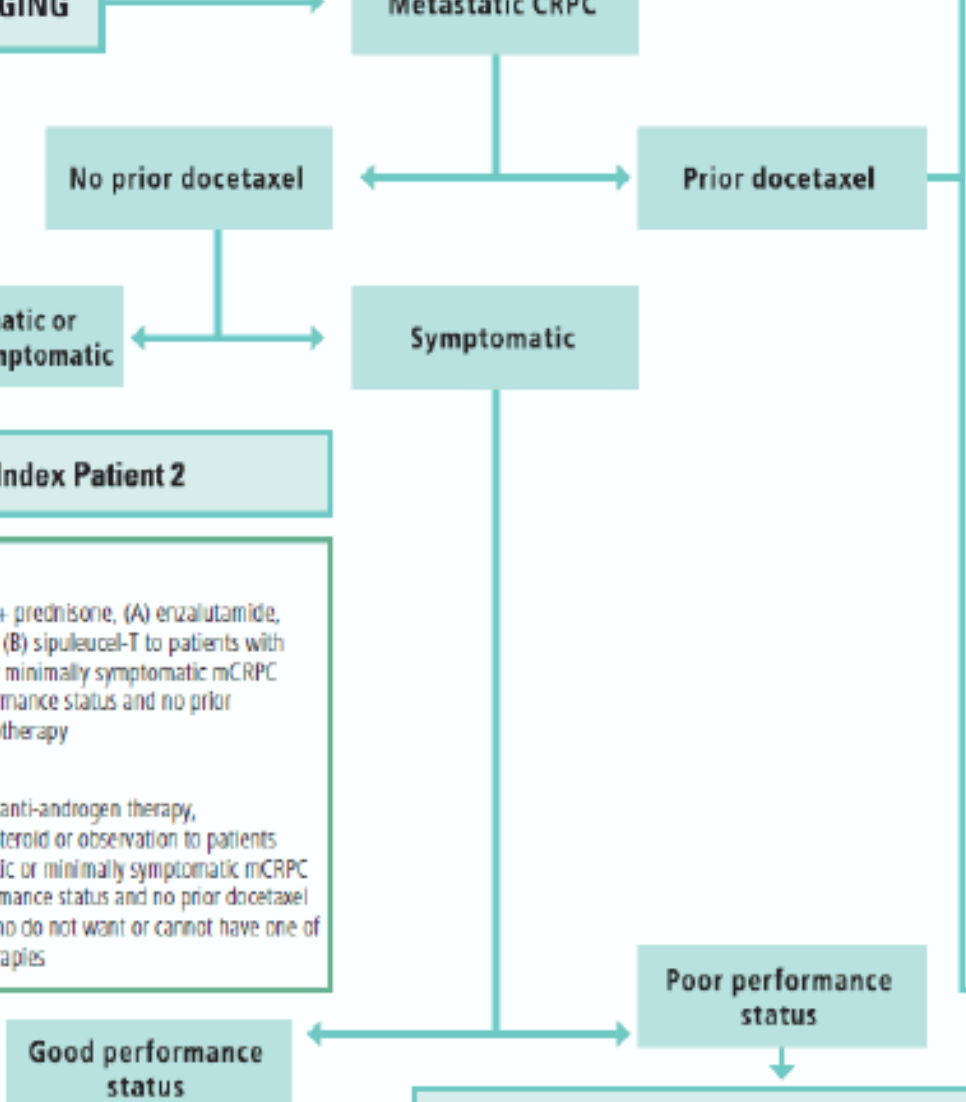

\begin{tabular}{|c|}
\hline Index Patient 3 \\
\hline STANDARD \\
\hline $\begin{array}{l}\text { (A) Abiraterone + prednisone, (A) ervalutamide, or (B) docetaxel to } \\
\text { patients with symptomatic, mCRPC with good performance status and no } \\
\text { prior docetaxel chemotherapy }\end{array}$ \\
\hline OPTION \\
\hline $\begin{array}{l}\text { (C) Ketoconazole + sterold, (B) mitoxantrone or (C) radionuclide therapy } \\
\text { to patients with symptomatic, mCRPC with good performance status and } \\
\text { no prio dacetaxel chembtherapy who do not want or cannot have one of } \\
\text { the standard therapies }\end{array}$ \\
\hline STANDARD \\
\hline $\begin{array}{l}\text { Padium-223 to paticents with symptoms from bony metastases } \\
\text { from mCAPC with good performance status and no pricr docetael } \\
\text { chemotherapy and without known visceral osease }\end{array}$ \\
\hline RECOMMENDAIION AGAINST \\
\hline $\begin{array}{l}\text { Estramustine or sipuleucel-T to patients with symptomatic, mCRPC with } \\
\text { good performance status and no prior docetaxel chemotherapy }\end{array}$ \\
\hline
\end{tabular}

\section{OPTION}

Ireatment with abiraterone + predrisone or enralutamide to patients with symptomatic, mCFPC with poor performance status and no prior docetael diemotherapy

Keloconazole + steroid or radionuclide therapy to patients with symptomatic, mCRPC with poor periormance status and no prior

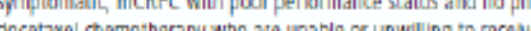

abiraterone + predisone or enzalutamide

EXPERT OPINION

Docetaxel or mitoxantrone chemotherapy to patients with symptomatic mCReC with poor perfiormance status and no prior docetaxel chemotherayy in select cases, specifically when the performance slatus is directly related to the cancer

\section{EXPERT OPINION}

Radum-223 to patienits with symptoms from bany melastases from mCRPC with poor pefformance status and no prior docetaxel chematherapy and without known visceral disease in select creses, specificaly when the performance status is directly related to syntotonis related to bone metastases

\section{RECOMMENDATION AGAINST}

Treatment with sipuleuced-T to patients with symptamatic, mCRPC with pror pesfontance status and no prior docetaxel chemotherapy
Good performance status

$\downarrow$

\section{Index Patient 5}

\section{STANDARD}

Treatnent with abiraterone + precurisone, cabazitasel of enzalutamide to patients with mCRPC with good performance status who hare received prior docetaxd chemotherapy If the patiant receined abiraterone + predrische priar to docetand chemotherapy, they should be offered cabazitaxel or enzalutamide

OPIION

Ketoconazole + steroid to patients with mCRPC with good perfomance status who received pricr docataxel if abir aterone + predrisone, cahazitaxel or enzalutamide is unzwalable OPIION

Retreatment with docetaxel to patients with mCARC with good pafformance status who were benefitting at the time of discontinuation (due to reversible side effects) of docetaxel chemotherapy

\section{STANDARD}

Radium-223 to patients with sympcorrs from bory melastases from ImCRPC with good perfonmance status who received prico docetarel chemotherary and without known uscral disease

\section{status}

Poor performance

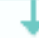

Index Patient 6

\section{EXPERT OPINION}

Palliative care to patients with mCRPC with poor pertormance status who received pror dacetzaxel chemotherapy. Alternatively, for sedected patients,

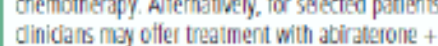
predisone, enzal utamide, ketoconarole + sleroid or radionuclide therapy

\section{EXPERT OPINION AGAINST}

Should not offer systernic chemotherapy or immunotherapy to patients with mCAPC with poor pertormance status who received pricr docataed chenothorapy

Figure 1:

Two recent randomized studies, CHAARTED and STAMPEDE showed benefit in the early administration of docetaxel along with ADT in men with metastatic hormone-sensitive prostate cancer (mHSPC). In the CHAARTED trial therapy with docetaxel plus ADT versus ADT alone was studied in 790 patients with MHSPC. OS was favorable in those treated with docetaxel plus ADT (57, 6 versus 40 months) [8]. Docetaxel showed higher improvement in OS if given with ADT in those patients with high volume disease (49, 2 vs. 32,2 months) [8]. High volume disease is defined as visceral metastases or at least 4 bone lesions, one of which should be outside the spine and pelvis. The results for low volume disease have not been published yet but seem less advantageous. STAMPEDE study encompasses both patients with metastatic PCa and non-metastatic PCa [9]. In this trialSOC (Standard of Care) treatment combined with radiotherapy in patients with high-risk NOMO disease was compared with SOC treatment combined with docetaxel. OS favored the second group (67 vs 77 months).
GETUG-AFU-15, a smaller study, didn't demonstrated any benefit in terms of OS. A combination of docetaxel with estramustine (ED, n=192) compared to androgen suppression alone (ADT, $n=193$ ) was analyzed. The results didn't showed significant benefit with respect to OS (58.9 vs 54.2 months respectively) [10].

In summary, SWOG-9916 and TAX-327 trials are the most important randomized studies showing the benefits of docetaxel in metastatic prostate cancer.

Cabazitaxel is a semi-synthetic taxane developed to overcome the resistance to docetaxel, because of its poor affinity for P-glycoprotein (P-gp), an ATP-dependent drug efflux pump. Cancer cells that express P-gp become resistant to taxanes, and the effectiveness of docetaxel may be limited by its high substrate affinity for P-gp [11]. This agent also has an extra methyl groups which 
provide cabazitaxel with an uncommon capacity among chemotherapy agents, the ability to cross the blood-brain barrier, the clinical effects of which remain to be investigated [12].

In order to assess the benefits of cabazitaxel, TROPIC study compared cabazitaxel with mitoxantrone in 755 patients previously treated with docetaxel. The primary endpoint was overall survival, which was 15.1 months in the cabazitaxel plus prednisone arm and 12.7 months in the mitoxantrone plus prednisone arm (Table 1) [13].Other secondary endpoints such as progressionfree survival, safety, tumor response, time to tumor progression and PSA response rate were all improved in the cabazitaxel arm [13]. Nonetheless, despite its clinical benefits, cabazitaxel encompasses several side effects. The most serious and common side effect is neutropenia, with neutropenic fever occurring in about $8 \%$ of patients. Patients over 65 years or with poor PS are at a higher risk of developing neutropenia than younger patients and in these cases concomitant use of growth factor should be considered [14].The degree of myelosuppression raises a question about whether a lower dose of cabazitaxel would be more appropriate. Other side effects may include diarrhea (6\%) and fatigue (5\%) [13].

FIRSTANA study was designed to test cabazitaxel as first line agent and randomized 1168 patients in three groups: cabazitaxel $20 \mathrm{mg} / \mathrm{m}^{2}$ (389 patients), cabazitaxel $25 \mathrm{mg} / \mathrm{m}^{2}$ (388 patients) and docetaxel (391 patients)(Table 2) [15]. In this study cabazitaxel failed to demonstrate superiority to docetaxel in terms of OS [15]. TAXYNERGY is a randomized trial of early switch from first-line docetaxel to cabazitaxel or vice versa with Circulating Tumor Cell (CTC) biomarkers in mCRPC patients [16].Patients changed therapy between taxanes if they did not reached a decline of PSA of more than $30 \%$ in the first 4 cycles of treatment [16]. Overall, 35 patients $(55,6 \%)$ had confirmed $\geq 50 \%$ PSA response. Patients with $\geq 50 \%$ PSA decline mean that Androgen Receptor Nuclear Localization (ARNL) in Circulating Tumor Cells (CTCs) decreased by $6,5 \%$, while in patients without this PSA decline ARNL in CTCs increased by 6,1\% (Table 2) [16]. The results of OS were not reached yet after a follow-up of 14 months. This trial was the first to report ARNL in CTCs as a correlative taxane activity biomarker [16].

Table 2 Promising new agents

\begin{tabular}{|c|c|c|c|c|}
\hline Medicine & Clinical Trial & Inclusion Criteria & Comparison & Results \\
\hline \multirow{2}{*}{ ARN-509 } & $\begin{array}{c}\text { SPARTAN } \\
\text { (NCT01946204) }\end{array}$ & CRPC & ARN-509 versus Placebo & Study in recruitment phase \\
\hline & NCT01171898 & $\begin{array}{l}\text { mCRPC with or without } \\
\text { pretreatment with AA }\end{array}$ & Various doses of the agent & No published results \\
\hline \multirow{2}{*}{ Cabazitaxel } & $\begin{array}{c}\text { FIRSTANA } \\
\text { (NCT01308567) }\end{array}$ & $\begin{array}{c}\text { mCRPC chemotherapy } \\
\text { naïve }\end{array}$ & $\begin{array}{c}\text { Cabazitaxel } 20 \mathrm{mg} / \mathrm{m}^{2} \text { versus } \\
\text { Cabazitaxel } 25 \mathrm{mg} / \mathrm{m}^{2} \text { versus } \\
\text { docetaxel }\end{array}$ & $\begin{array}{c}24,5 \text { vs } 25,2 \text { vs } 24,3 \text { months, } \\
\text { respectively }\end{array}$ \\
\hline & $\begin{array}{c}\text { TAXYNERG } \\
\text { (NCT01718353) }\end{array}$ & $\begin{array}{l}\text { mCRPC chemotherapy } \\
\text { naïve }\end{array}$ & $\begin{array}{c}\text { Cabazitaxel + Prednisona versus } \\
\text { Docetaxel + Prednisona (It was } \\
\text { allowed to exchange between } \\
\text { taxanes) }\end{array}$ & $\begin{array}{c}35 \text { patients }(55,6 \%) \text { had } \\
\text { confirmed } \geq 50 \% \text { PSA response }\end{array}$ \\
\hline \multirow{2}{*}{ Cabozantinib (XL184) } & $\begin{array}{c}\text { COMET-1 } \\
\text { (NCT01605227) }\end{array}$ & $\begin{array}{l}\text { mCRPC after docetaxel } \\
\text { and agents directed to } \\
\text { ARs }\end{array}$ & Cabozantinib versus Placebo & $\begin{array}{c}\text { Completed study OS: } 11,0 \text { vs } 9,8 \\
\text { months }\end{array}$ \\
\hline & $\begin{array}{c}\text { COMET-2 } \\
\text { (NCT01522443) }\end{array}$ & $\begin{array}{l}\text { mCRPC with bone } \\
\text { pain from metastases, } \\
\text { uncontrolled with opioid }\end{array}$ & $\begin{array}{l}\text { Abozantinib versus } \\
\text { Mitoxantrona }\end{array}$ & $\begin{array}{l}\text { The pain results rates (15\% vs } \\
17 \% \text { ) OS ( } 9 \text { vs } 7,9 \text { months) }\end{array}$ \\
\hline
\end{tabular}

\section{Hormonal agents}

Although medical or surgical castration, extragonadal sites such as adrenal gland continuously maintains its androgen production [17].

Abiraterone Acetate (AA) is an oral agent that is a key regulator of extragonadal androgen biosynthesis and potently blocks cytochrome P450c17 (CYP17) and, through this inhibition, blocks the conversion of cholesterol into testosterone and Dihydrotestosterone (DHT). By inhibiting the biochemical pathway of cholesterol and preventing adrenal insufficiency, AA should always be given along with prednisone.

The phase III COU-AA-301 trial evaluated abirateroneand prednisone (2:1) versus prednisone in 1195patients with metastatic CRPC pretreated with docetaxel. Significant differences in OS (14, 8 vs 10, 9 months) were seen, favoring targeted therapy and representing a $26 \%$ reduction in the risk of death, as well as significant improvements in radiographic progression-free survival, time to PSA progression and PSA responses (Table 1) [18].

The main adverse effects grade III/IV were fatigue $(8 \%$ and $<1 \%)$, anemia ( $8 \%$ and $<1 \%$ ), hypokalemia ( $3 \%$ and $<1 \%)$, hypertension $(1 \%$ and $0 \%)$, and lower limbs edemas $(2 \%$ and $<1 \%)$, secondary to excess mineral corticoids, which improves with an addition of a mineral corticoid receptor antagonist such as eplerenone or prednisone, in order to normalize ACTH levels [18].

Due to the benefit reached with abiraterone in the post-chemotherapy setting COU-AA-302 study was carried in chemotherapy naïve patients [19].The phase III COU-AA-302 trial compared (1:1)abiraterone plus prednisone versus prednisone alone in asymptomatic or mildly symptomatic chemo-naïve and ketoconazole-naive metastatic CRPC patients without visceral disease and with only bone or lymphnode metastases [19]. AA showed clinical benefits and was associated with a delay in disease progression and a significant improvement in 
overall survival at 49 months of follow-up, despite the fact that $44 \%$ of patients in the placebo arm crossed over to active abiraterone (Table 1) [19].

Enzalutamide, previously known as MDV-3100, is a potent oral antagonist of non-steroidal ARs (Androgen Receptor) [20]. This hormonal agent possesses three mechanisms of action: blocks testosterone action by binding the AR, impairs nuclear translocation of the AR and inhibits its association with DNA [20]. Importantly, the drug maintains a strong activity as an antagonist even in patients in a castration-resistant phase, unlike other anti-androgens that only exhibit partial agonist activity before the ARs [20]. In addition to the aforementioned mechanisms, enzalutamide further avoids the transference of ARs from the cytoplasm (where they are inactive) to the core (where they act as transcriptional factors), thereby preventing the interaction between the AR and the transcriptional complex [21]. Compared with abiraterone, enzalutamide doesn't need the concomitant administration of a corticosteroid. Strinkingly, enzalutamide may be less effective if given with prednisone -this phenomenon may be due to the promiscuous activation of ARs by prednisone or direct agonism of the glucocorticoid receptor [22].

A phase III study (AFFIRM) in patients with mCRPC pretreated with docetaxel showed a benefit in OS in patients treated with enzalutamide compared to those under placebo (18,4 vs 13,6 months), even though there was as unblinding after an interim analysis and patients on placebo were allowed to cross-over to receive enzalutamide (Table 1)[23]. That 4.8-month difference in OS translated in a 37\% reduction in the risk of death of any cause in the enzalutamide arm. Enzalutamide was approved by the FDA and EMA in August 2012 and June 2013 for the treatment of patients with MCRPC in the post-chemotherapy setting, based on the results of the AFFIRM study (Figure 1). After this achievement, another phase III study (PREVAIL) was implemented to evaluate the safety and effectiveness of enzalutamide over placebo, in chemotherapy-naïve patients [24]. The results were once again encouraging as enzalutamide reduced the risk of death by $29 \%$ and the risk of radiographic progression by $81 \%$ and this AR antagonist was approved for all patients with mCRPC (Table 1), regardless of whether they had undergone previous chemotherapy (FDA approval in September 2014, EMA approval in December 2014 (Figure 1)).

Despite these excellent results, many patients treated with abiraterone and enzalutamide develop resistance to these therapies and our knowledge of the pathogenesis of resistance to these agents is improving but, until now, extremely, limited [25]. According to Antonarakis et al., detection of androgenreceptor splice variant 7 messenger RNA (AR-V7) in circulating tumor cells may be associated with resistance to enzalutamide and abiraterone in patients with CRPC [26].

\section{Bone Targeted Agents}

Bone metastases have a significant impact on men with mCRPC and are an important cause of pain and poor quality of life.
Osteoporosis related to androgen suppression is also associated with an increased risk of fractures. Until recently, zoledronic acid was the only bone targeted agent available to reduce bone pain and the number of skeletal related events and to increase bone mineral density in patients receiving long-term ADT $[27,28]$.

Denosumab is a monoclonal antibody directed to human RANKL [29]. A phase III study revealed the superiority of denosumab over zoledronic acid regarding the prevention of bone events in patients with $\mathrm{MCRPC}$ - more time is needed for the occurrence of the first bone event when denosumab is used $(20,7$ vs 17,1 months) (Table 1) [29]. Furthermore, unlike zoledronic acid, denosumab doesn't require dosage adjustment or monitoring of renal function. Due to the results of this and two other studies (for the treatment of breast cancer and other metastatic solid tumors), FDA and EMA approved it for the prevention of skeletal related events in patients with bone metastasis in solid tumors in November 2010 and July 2011 respectively.

Radium-223 (alpharadin) is a high energy and short-range $\alpha$ particles emitter radiopharmaceutical calcium that induces dsDNA rupture after uptake by bone tissue (and particularly by osteoblastic metastases). ALSYMPCA, a phase III clinical trial, tested the efficacy of alpharadincompared to placebo in patients with mCRPC and bone metastases, who had previously received docetaxel or who were not candidates for chemotherapy [30]. Alpharadin showed an increase of $30 \%$ in OS (14, 9 vs 11,3 months) and a prolonged time to first skeletal related event with a favorable safety profile (Table 1) [30]. Due to the results of this study, alpharadin was approved by the FDA in May 2013 and EMA in November 2013 for the treatment of CRPC with symptomatic bone metastases in the absence of visceral metastases.

Immunotherapy: An alternative or complementary strategy is the use of immunologically active agents, which may be advantageous to allow the immune system to generate an antitumor response [31].

Sipuleucel-T is a personalized vaccine that is derived from autologous CD54+ dendritic cells, which are removed from the blood of individuals and processed with a recombinant fusion protein composed of PAP (Prostatic Acid Phosphatase) and GM-CSF (Granulocyte Macrophage Colony Stimulating Factor) with the objective of stimulating an immune response against prostate cancer cells.

A phase III trial (IMPACT) was conducted in patients with MCRPC and the results favored the group treated with the vaccine compared to those who received placebo regarding OS (25, 8 vs 21,7 months) (Table 1) [31]. This study led to approval of this vaccine in April 2010 and in September 2013 by FDA and EMA, respectively (Figure 2). However, this vaccine has limitations like the cost and its complex production and for these reasons Sipuleucel-T penetrance in Europe has been scarce.

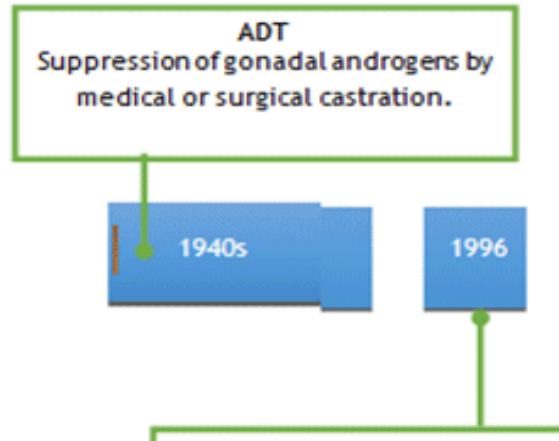

Mitoxantrone Approved for the treatment of symptomatic $\mathrm{mCRPC}$.

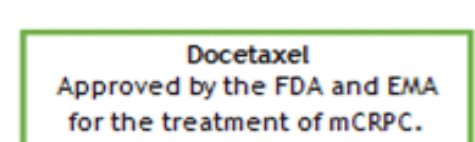

Sipuleucel-T Approved by the FDA for the treatment of men with asymptomatic or mildty symptomatic $\mathrm{mCRPC}$.
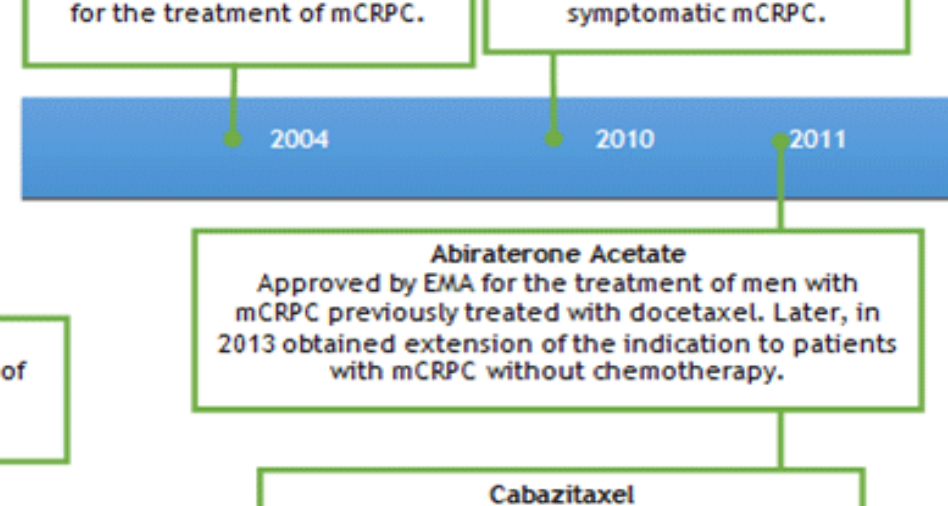

Cabazitaxel

Approved by EMA in 2011 for the treatment

of $\mathrm{mCRPC}$ previously treated with docetaxel
Enzalutamide
Approved by the FDA in 2012 and by the EMA in 2013 for treatment of men with $\mathrm{mCRPC}$ previously treated with docetaxel. Later, in 2014 obtained extension of the indication for use in patients with $\mathrm{mCRPC}$ without chemotherapy.

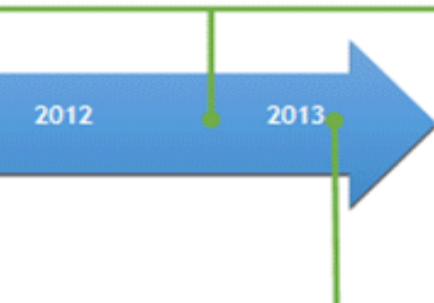

Radium-223 (alpharadin) Approved by FDA and EMA in 2013 for the treatment of CRPC with symptomatic bone metastases in the absence of visceral metastases

Figure 2: Timeline of approved agents 
ProstVac-VF is a vaccine reconstituted from two recombinant viral vectors encoding the transgenes for PSA, and three co-stimulatory molecules (B7.1, ICAM-1 and LFA-3), all together capable of motivating local immune response [32].

ProstVac-VF is subcutaneously injected and was evaluated in PROSPECT, a phase III trial involving patients with mCRPC chemotherapy-naïve asymptomatic or mildly symptomatic [32]. Patients were randomized into three groups: ProstVac-VF versus ProstVac-VF plus subcutaneous GM-CSF versus placebo [33]. By January 2015, the study had been fully enrolled with 1.297 mCRPC patients from 15 countries and the final results are expected this year [34].

Ipilimumab is an anti-CTLA-4 monoclonal antibody that inhibits tumor cell evasion of the host immune activity [35]. A phase III studies (CA184-043) involving patients with mCRPC who received prior chemotherapy didn't showed significant improvements regarding OS when compared with placebo [36]. Per these results this monoclonal antibody has not yet been approved for use in patients with mCRPC.

\section{Promising New Agents}

The modest efficacy of the agents already approved impulses the development of new agents that may change even more the course of the disease.

Apalutamide, previously known as ARN-509, is a pure antagonist of ARs that also prevents, similarly to enzalutamide nuclear translocation of AR and it's binding to the DNA [37]. This new signaling inhibitor may have advantages over enzalutamide since it doesn't cross the blood-brain barrier and may avoid seizures. Clinical trials are underway to assess the efficacy of apalutamide in patients with non-metastatic CRPC and mCRPC with or without upfront chemotherapy (Table 2) $[38,39]$.

Cabozantinib (XL184) is a tyrosine kinase inhibitor that inhibits both c-Met pathway and VEGFR2. C-MET is a cell surface receptor for Hepatocyte Growth Factor (HGF) and the signaling HGF/c-MET is important in many physiological processes such as embryogenesis, organogenesis, angiogenesis, among others [40]. This signaling pathway also promotes evasion to immunity, motility and formation of metastases by structural changes in the cytoskeleton and modification of the expressed integrins [40]. There are two phase III studies in men with progressive disease after docetaxel and at least one new hormonal agent (abiraterone or enzalutamide). The first study (COMET-1), designed to evaluate the efficacy of cabozantinib with prednisone versus placebo showed favorable OS in the group treated with cabozantinib (11, 0 vs. 9,8 months), even though there were no improvements in PSA levels (Table 2)[41]. The other study (COMET-2) aims to investigate the effects of cabozantinib versus mitoxantrone/prednisone (MP) at quality of life and pain control in patients with mCRPC with moderate to severe pain who were previously treated with docetaxel and abiraterone or enzalutamide [42]. The pain results rates were $15 \%$ for cabozantinib versus $17 \%$ for MP, bone scan response was 31\% for cabozantinib versus 5,2\% for MP. OS outcome favored the group treated with cabozantinib (9, 0 vs. 7,9 months) (Table 2) [42]. Nonetheless, the primary endpoint of improving pain response was not achieved in this heavily pretreated population. The key secondary endpoints of BSR and OS showed, however, trends favoring cabozantinib arm [42].

This new era of treatment seems to improve OS in patients with mCRPC. Nevertheless, further studies with longer follow up will unveil the costs (side effects and economical) of these approaches when compared to their clinical benefits Still, the optimal time point to initiate or stop treatment remains uncertain [43] Nevertheless, combination therapy, by adding synergistic hormonal, cytotoxic and bone protection, may be the future in the management of CRPC.

There are several agents approved for the treatment of mCRPC (Table 1), while others are promising future agents (table 2). Among the promising agents cabazitaxel, which was previously approved as second line treatment for mCRPC, showed also some beneficial results as a first line agent in the treatment of mCRPC. In figure 1 it is possible to observe the date of approval of the main drugs and for which situations these are recommended.

\section{Conclusion}

The treatment paradigm of prostate cancer is continuously evolving and increasing knowledge about the pathogenesis and heterogeneity of this disease is leading to new approaches that include both old and new agents.

Recent years brought the development of a wide a range strategies for the treatment of mCRPC. Both hormonal therapy and chemotherapy target AR signaling have been shown to corroborate the importance of the AR axis in the treatment of prostate cancer.

Currently there is a wide range of therapeutic options for mCRPC; still, there remain questions about optimal sequencing and the association of these therapies, all subjects of ongoing and future studies, even though combination may be the way in castrate resistant prostate cancer. Future biomarkers and genetic signatures might improve our abilities in selecting patients and tailored treatments.

\section{References}

1. Jemal A, Siegel R, Xu J, Ward E. Cancer statistics, 2010. CA Cancer J Clin. 2010;60(5):277300. doi: $10.3322 /$ caac. 20073

2. Mottet N, Bellmunt J, Bolla M, Joniau S, Mason M, Matveev V, et al. EAU guidelines on prostate cancer. Part II: Treatment of advanced, relapsing, and castration-resistant prostate cancer. Eur Urol. 2011;59(4):572-583. doi: 10.1016/j.eururo.2011.01.025

3. Manni A, Bartholomew M, Caplan R, Boucher A, Santen R, Lipton A, et al. Androgen priming and chemotherapy in advanced prostate cancer: evaluation of determinants of clinical outcome. J Clin Oncol. 1988;6(9):1456-1466. doi: 10.1200/JC0.1988.6.9.1456

4. Cookson MS, Roth BJ, Dahm P, Engstrom C, Freedland SJ, Hussain M, et al. Castrationresistant prostate cancer: AUA guideline. J Urol. 2013;190(2):429-438. doi: 10.1016/j. juro.2013.05.005

5. Martel CL, Gumerlock PH, Meyers FJ, Lara PN. Current strategies in the management of hormone refractory prostate cancer. Cancer Treatment Reviews. 2003;29(3):171-187. doi: 10.1016/S0305-7372(02)00090-7

6. Tannock IF, de Wit R, Berry WR, Horti J, Pluzanska A, Chi KN, et al. Docetaxel plus prednisone or mitoxantrone plus prednisone for advanced prostate cancer. N Engl J Med. 2004;351(15):1502-1512. doi: 10.1056/NEJMoa040720

7. Petrylak DP, Tangen CM, Hussain MH, Lara PN Jr, Jones JA, Taplin ME, et al. Docetaxel and estramustine compared with mitoxantrone and prednisone for advanced refractory prostate cancer. N Engl J Med. 2004;351(15):1513-1520. doi: 10.1056/NEJMoa041318

8. Sweeney CJ, Chen Y-H, Carducci M, Liu G, Jarrard DF, Eisenberger M, etal. Chemohormonal therapy in metastatic hormone-sensitive prostate cancer. Urol Oncol. 2017;35(3):123. doi: 10.1016/j.urolonc.2016.12.021

9. James ND, Sydes MR, Clarke NW, Mason MD, Dearnaley DP, Spears MR, et al. Addition of docetaxel, zoledronic acid, or both to first-line long-term hormone therapy in prostate cancer (STAMPEDE): Survival results from an adaptive, multiarm, multistage, platform randomised controlled trial. Lancet. 2016;387(10024):1163-1177.

10.Gravis G, Fizazi K, Joly F, Oudard S, Priou F, Esterni B, et al. Androgen-deprivation therapy alone or with docetaxel in non-castrate metastatic prostate cancer (GETUGAFU 15): a randomised, open-label, phase 3 trial. Lancet Oncol. 2013;14(2):149-58. doi: 10.1016/S1470-2045(12)70560-0

11.Bissery MC. Preclinical evaluation of new taxoids. Curr Pharm Des. 2001;7(13):12511257

12.Kingston DG. Tubulin-interactive natural products as anticancer agents. J Nat Prod. 2009;72(3):507-15. doi: 10.1021/np800568j

13.de Bono JS1, Oudard S, Ozguroglu M, Hansen S, Machiels JP, Kocak I, et al. Prednisone plus cabazitaxel or mitoxantrone for metastatic castration-resistant prostate cancer progressing after docetaxel treatment: a randomised open-label trial. Lancet. 2010;376(9747):1147-1154. doi: 10.1016/S0140-6736(10)61389

14. Mohler JL, Armstrong AJ, Bahnson RR, Boston B, Busby JE, D’Amico AV, et al. Prostate cancer, Version 3.2012: featured updates to the NCCN guidelines. J Natl Compr Canc Netw. 2012;10(9):1081-1087.

15.C. Cabazitaxel No Better Than Docetaxel in Metastatic. 2016;2-3.

16.Pal SK, Hauke RJ, Sonpavde G, Oh WK, Bhardwaj N, Gnjatic S. Published on. 2016;15(D):10-11.

17.Molina A, Belldegrun A. Novel therapeutic strategies for castration resistant prostate cancer: inhibition of persistent androgen production and androgen receptor mediated signaling. J Urol. 2011;185(3):787-794. doi: 10.1016/j.juro.2010.10.042

18.de Bono JS, Logothetis CJ, Molina A, Fizazi K, North S, Chu L, et al. Abiraterone and increased survival in metastatic prostate cancer. N Engl J Med. 2011;364(21):19952005. doi: 10.1056/NEJMoa1014618.

19.Ryan CJ, Smith MR, de Bono JS, Molina A, Logothetis CJ, de Souza P, et al. Abiraterone in metastatic prostate cancer without previous chemotherapy. $\mathrm{N}$ Engl J Med. 
2013;368(2):138-148. doi: 10.1056/NEJMoa1209096

20.Watson PA, Chen YF, Balbas MD, Wongvipat J, Socci ND, Viale A, et al. Constitutively active androgen receptor splice variants expressed in castration-resistant prostate cancer require full-length androgen receptor. Proc Natl Acad Sci U S A. 2010;107(39):1675916765. doi: 10.1073/pnas.1012443107

21.Tran C, Ouk S, Clegg NJ, Chen Y, Watson PA, Arora V, Wongvipat J, et al. Development of a second-generation antiandrogen for treatment of advanced prostate cancer. Science. 2009;324(5928):787-790. doi: 10.1126/science.1168175

22.Scher HI, Fizazi K, Saad F, Chi KN, Taplin M, Sternberg CN, et al. Impact of on-study corticosteroid use on efficacy and safety in the phase III AFFIRM study of enzalutamide (ENZA), an androgen receptor inhibitor. ASCO Meet Abstr. 2013;31(6_suppl):6.

23.Scher HI, Fizazi K, Saad F, Taplin ME, Sternberg CN, Miller K, et al. Increased survival with enzalutamide in prostate cancer after chemotherapy. N Engl J Med. 2012;367(13):1187 1197.

24.Beer TM, Armstrong AJ, Rathkopf DE, Loriot Y, Sternberg CN, Higano CS, et al. Enzalutamide in metastatic prostate cancer before chemotherapy. $\mathrm{N}$ Engl J Med. 2014;371(5):424-433. doi: 10.1056/NEJMoa1405095

25.Recine F, Sternberg CN. Hormonal therapy and chemotherapy in hormone-naive and castration resistant prostate cancer. Transl Androl Urol. 2015;4(3):355-364. doi: 10.3978/j.issn.2223-4683.2015.04.11

26.Antonarakis ES, Lu C, Wang H, Luber B, Nakazawa M, Roeser CJ, et al. AR-V7 and Resistance to Enzalutamide and Abiraterone in Prostate Cancer. N Engl J Med 2014;371:1028-1038.

27.Saad F, Gleason DM, Murray R, Tchekmedyian S, Venner P, Lacombe L, et al. Long-term efficacy of zoledronic acid for the prevention of skeletal complications in patients with metastatic hormone-refractory prostate cancer. J Natl Cancer Inst. 2004;96(11):879882.

28.Smith MR, Eastham J, Gleason DM, Shasha D, Tchekmedyian S, Zinner N. Randomized controlled trial of zoledronic acid to prevent bone loss in men receiving androgen deprivation therapy for nonmetastatic prostate cancer. J Urol. 2003;169(6):2008-2012.

29.Fizazi K, Carducci M, Smith M, Damião R, Brown J, Karsh L, et al. Denosumab versus zoledronic acid for treatment of bone metastases in men with castration-resistant prostate cancer: a randomised, double-blind study. Lancet. 2011;377(9768):813-822. doi: 10.1016/S0140-6736(10)62344-6

30.Parker C, Nilsson S, Heinrich D, Helle SI, O’Sullivan JM, Fosså SD. Alpha emitter radium-223 and survival in metastatic prostate cancer. N Engl J Med. 2013 Jul 18;369(3):213-223. doi: 10.1056/NEJMoa1213755

31.Drake CG. Prostate cancer as a model for tumour immunotherapy. Nat Rev Immunol. 2010;10(8):580-593. doi: 10.1038/nri2817
32.Kantoff PW, Higano CS, Shore ND, Berger ER, Small EJ, Penson DF, et al. Sipuleucel-T immunotherapy for castration-resistant prostate cancer. N Engl J Med. 2010;363(5):411422. doi: 10.1056/NEJMoa1001294

33.DiPaola RS, Plante M, Kaufman H, Petrylak DP, Israeli R, Lattime E, et al. A phase I trial of pox PSA vaccines (PROSTVAC-VF) with B7-1, ICAM-1, and LFA-3 co-stimulatory molecules (TRICOM) in patients with prostate cancer. J Transl Med. 2006;4:1. doi: 10.1186/1479-5876-4-1

34.ClinicalTrials.gov registry. A Randomized, Double-blind, Phase 3 Efficacy Trial of PROSTVACV/F +/- GM-CSF in Men With Asymptomatic or Minimally Symptomatic Metastatic Castrate-Resistant Prostate Cancer (Prospect) identifier NCT01322490.

35.Salama AK, Hodi FS. Cytotoxic T-lymphocyte-associated antigen-4. Clin Cancer Res. 2011;17(14):4622-4628. doi: 10.1158/1078-0432.CCR-10-2232

36.Drake CG, Kwon ED, Fizazi K, Bossi A, Alfons JM van den Eertwegh, Christopher Logothetis, et al. Results of subset analyses on overall survival (OS) from study CA184043: Ipilimumab versus placebo in postdocetaxel metastatic castration-resistant prostate cancer (mCRPC). J Clin Oncol. 2014;32(Suppl.):abstract 2.

37.Rathkopf DE, Morris MJ, Fox JJ, Danila DC, Slovin SF, Hager JH. Phase I study of ARN-509, a novel antiandrogen, in the treatment of castration-resistant prostate cancer. J Clin Oncol. 2013;31(28):3525-3530. doi: 10.1200/JC0.2013.50.1684

38.ClinicalTrials.gov registry. A Study of ARN-509 in Men With Non-Metastatic CastrationResistant Prostate Cancer (SPARTAN) identifier NCT01946204.

39.ClinicalTrials.gov registry. Safety, Pharmacokinetic and Proof-of-Concept Study of ARN509 in Castration-Resistant Prostate Cancer (CRPC) identifier NCT01171898.

40.Scagliotti GV, Novello S, von Pawel J. The emerging role of MET/HGF inhibitors in oncology. Cancer Treat Rev. 2013;39(7):793-801. doi: 10.1016/j.ctrv.2013.02.001

41.Tannock IF, Fizazi K, Ivanov S, Karlsson CT, Fléchon A, Skoneczna I, et al. Aflibercept versus placebo in combination with docetaxel and prednisone for treatment of men with metastatic castration-resistant prostate cancer (VENICE): a phase 3, doubleblind randomised trial. Lancet Oncol. 2013;14(8):760-768. doi: 10.1016/S14702045(13)70184-0

42.Kelly WK, Halabi S, Carducci M, George D, Mahoney JF, Stadler WM, et al. Randomized, double-blind, placebo-controlled phase III trial comparing docetaxel and prednisone with or without bevacizumab in men with metastatic castration-resistant prostate cancer: CALGB 90401. J Clin Oncol. 2012;30(13):1534-1540. doi: 10.1200/ JCO.2011.39.4767

43.APCCC 2017: Advance Prostate Cancer Consensus Conference 2017 - Session 3, Talk 3 - What is the optimal time to change treatment inmen with mCRPC, Karim Fizazi, 9th March 2017. 